\title{
Genetic diversity and phylogenetic relationships of Malayan tapir (Tapirus indicus) populations in the Malay Peninsula based on mitochondrial DNA control region
}

\author{
Qi Luan Lim ${ }^{1,2}$ - Christina Seok Yien Yong ${ }^{1}$ (D) Wei Lun $\mathrm{Ng}^{3}$ (D) Ahmad Ismail ${ }^{1}$. \\ Jeffrine J. Rovie-Ryan ${ }^{4,5}$ • Norsyamimi Rosli ${ }^{4}$ Geetha Annavi ${ }^{1}$ (D)
}

Received: 23 June 2020 / Revised: 13 April 2021 / Accepted: 17 May 2021 /

Published online: 31 May 2021

(C) The Author(s), under exclusive licence to Springer Nature B.V. 2021

\begin{abstract}
The Malayan tapir (Tapirus indicus) is an endangered species in Southeast Asia (SEA). Over the years, there has only been a few reports on its population genetic structure and evolutionary history in SEA. In particular, while the captive Malayan tapir population in Thailand has received fairly more research in recent years, there has not been any widescale population genetic study in the Malay Peninsula since the last decade. In this study, we report on the genetic diversity and attempt to make inferences on the phylogeography of the Malayan tapir in the Malay Peninsula, using the mitochondrial DNA control region, including also data from previous studies. We identified 12 novel haplotypes and two distinct Malayan tapir clades with a divergence time of 14.6 million years ago (mya) in the Peninsular Malaysia (i.e. southern Malay Peninsula) samples, as opposed to only one clade found in the Thai (i.e. Thailand western border and northern Malay Peninsula) captive individuals, with an almost two-fold higher nucleotide diversity compared to the latter. The co-occurrence of the two lineages in southern Malay Peninsula suggested past historical events of population isolation, migration and admixture as a result of episodic glacial periods and paleoenvironmental changes in SEA. Only one haplotype shared between the populations of the two regions suggested further gene flow restriction at the narrow corridor of the Malay Peninsula as of present day.
\end{abstract}

Keywords D-loop · Asian tapir · Peninsular Malaysia · Thailand · Population genetic structure

Communicated by Pradeep Kumar Divakar.

Geetha Annavi

geetha@upm.edu.my

Extended author information available on the last page of the article 